Z Epileptol 2011 $24: 305-305$

DOI 10.1007/s10309-011-0203-9

Online publiziert: 11. September 2011

(c) Springer-Verlag 2011

\title{
J. Klepper
}

Kinderklinik, Klinikum Aschaffenburg, Aschaffenburg

\section{Ketogene Diåt im praktischen Alltag}

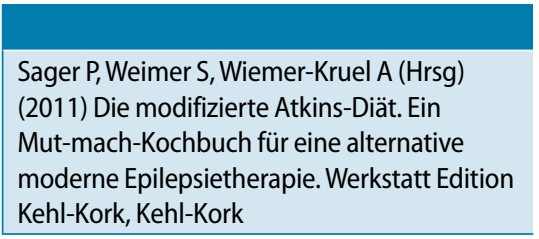

Das vorgestellte Mut-mach-Kochbuch zur modifizierten Atkins-Diät war längst überfällig - seit Langem erwarten Eltern Hilfe zur Umsetzung dieser ketogenen Diät im praktischen Alltag.

Die modifizierte Atkins-Diät erweitert das Spektrum ketogener Diäten, die in der Therapie pharmakorefraktärer Epilepsien gut etabliert sind. Bisher fehlte jedoch eine Rezeptbuchsammlung. Das Mut-mach-Kochbuch bietet diese in übersichtlicher Form, erweitert durch einen allgemeinen Einleitungsteil und eine gute Übersicht über allgemeine Hilfen, weiterführende Internetseiten, Bücher und Fachliteratur. Die Rezepte sind übersichtlich, z. T. mit appetitlichen Bildern dargestellt. Der diätetische Aspekt ist auf die Angabe der Kohlenhydrate von Zutaten und Gesamtrezept in sinnvoller Weise begrenzt. Der Inhalt ist nach Tagesmahlzeiten gegliedert. Auch der Bezugspreis von ca. 20 Euro ist anwenderfreundlich. Das Mut-mach-Kochbuch wird vielen Familien helfen, die modifizierte Atkins-Diät erfolgreich im Alltag umzusetzen - die Einschränkung, dass diese Diät nur unter ärztlicher und diätetischer Anleitung durchzuführen ist, wird im Buch ausdrücklich hervorgehoben. Somit dient dieses Buch auch dem behandelnden Arzt als gutes Hilfsmittel bei der Instruktion von betroffenen Patienten und deren Familien.

Jörg Klepper, Aschaffenburg

\section{Korrespondenzadresse \\ PD Dr. J. Klepper}

Kinderklinik, Klinikum Aschaffenburg Am Hasenkopf, 63739 Aschaffenburg Joerg.klepper@klinikum-aschaffenburg.de

Interessenkonflikt. Der korrespondierende Autor weist auf folgende Beziehung hin: Referententätigkeit für SHS Nutricia, Heilbronn. 